ORIGINAL ARTICLE

\title{
Informed consent in renal transplantation
}

\author{
A G Edwards, A R Weale, J D Morgan
}

Postgrad Med J 2005;81:188-190. doi: 10.1136/pgmj.2004.024760

Purpose: This study was performed to assess how well completed the new consent forms are for patients undergoing renal transplantation.

Methodology: 100 patients were randomly selected from the 160 who had a renal transplantation, at a

See end of article for authors' affiliations

.....................

Correspondence to: Miss A Edwards,

Department of Surgery, Southmead Hospital, Bristol BS10 5NB, UK: dr_ag_edwards@yahoo. com

Submitted 1 June 2004 Accepted 18 June 2004 single centre in the UK, over an 18 month period. The notes were located and the consent forms scrutinised.

Findings: Seven sets of notes could not be traced and 10 did not contain a relevant consent form. Forty eight per cent of completed forms mentioned the source of organ while $8 \%$ mentioned on which side the operation was to be performed. Twelve risks and complications were identified as being relevant to this procedure but no single form mentioned all 12. In most cases a senior member of the surgical team obtained consent.

Implications: The demonstrated variability in the amount of detail on consent forms lends weight to the call for the use of procedure specific forms. While such variability does not necessarily equate with not gaining valid, informed consent, this form, at present, serves as the only record of what has been discussed with the patient. These findings should encourage all surgeons to complete the forms themselves, be as detailed as possible, and ensure that the form is filed in the patients' notes.
$\mathrm{T}$ he requirement to obtain valid, informed consent before surgery is becoming increasingly more important with patients demanding more information and the courts applying tougher standards on what information should be provided by doctors.

The government's NHS Plan promised a review of consent procedures to ensure that good practice in seeking consent, for both treatment and research, is in place throughout the NHS. In April 2002, the Department of Health introduced a series of new consent forms, nationally, in an attempt to improve the process. ${ }^{1}$ The form for adults consenting to treatment, form one, contains a section for the recording of benefits and "serious or frequently occurring risks".

This study was carried out to assess how well completed these new consent forms are, in the 18 months since their introduction, for patients undergoing renal transplantation at a single unit in the UK

\section{METHOD}

A total of 100 sets of notes were randomly selected from those of the 160 adults who had renal transplantation at Southmead Hospital, Bristol between April 2002 and November 2003. The consent form was located in each set of notes and assessed in the following areas:

- Proposed procedure

- Intended benefits

- Risks

- Doctor obtaining consent

\section{RESULTS}

Of the 100 sets of notes chosen seven could not be traced and 10 did not contain a consent form pertaining to a renal transplant. The remaining 83 sets of notes all contained a consent form. Forty consent forms (48\%) mentioned the source of organ (living, cadaveric, non-heart beating) to be transplanted. This was more likely to be mentioned for patients receiving an organ from a living donor, 21 of 24 forms $(88 \%)$, as compared with those receiving one from a cadaveric or non-heart beating donor, 19 of 59 forms (32\%) $\left(p \leqslant 0.001, \chi^{2}\right)$. Only seven forms $(8 \%)$ mentioned on which side the operation was to be performed. Most of the forms, 75 $(90 \%)$, mentioned at least one valid benefit of the surgery.

Twelve different risks and complications were identified as being relevant to this procedure (table 1) but none of the forms mentioned all 12. The mean number of complications mentioned per form was 3.47 (range 1-6) for the 21 forms relating to "elective" transplants, from living donors. For the forms dealing with "emergency" transplants, with organs from cadaveric and non-heart beating donors, the mean number of complications mentioned was 3.43 (range 0-8). One surgical consultant also distributed an information leaflet to three of the patients that he consented for the procedure.

One form had not been signed by a member of staff, but had been by the patient. In $86 \%$ of cases surgical staff obtained consent while the renal physicians were responsible for the completion of the other 11 forms (table 2). In all cases the consent form was completed on the day of or the day before surgery.

\section{DISCUSSION}

The issues of informed consent within the field of transplantation are unique, as permission must be obtained for both the donor and recipient procedures. After a number of high profile cases in the UK, in Bristol ${ }^{2}$ and Liverpool, ${ }^{3}$ concerns have been raised regarding the quality of consent gained for the removal of tissue and organs from patients. As such, gaining consent in this part of the transplantation process is tightly regulated. In response to these inquiries a new piece of legislation is currently being introduced to address the concerns raised. ${ }^{4}$ This Human Tissue Bill will deal predominantly with the use of tissue for research and training purposes, but will also cover organ donation, both living and cadaveric. At present the content of the bill is still being debated and it is not certain whether any significant changes relating to organ donation will be implemented. However, the principles of gaining informed consent for the implantation 


\begin{tabular}{|c|c|c|}
\hline Potential risks/complications & Mentioned & None mentioned \\
\hline Bleeding & 37 & 46 \\
\hline Delayed function and need for dialysis & 14 & 69 \\
\hline Acute rejection & 58 & 25 \\
\hline Biopsies & 8 & 75 \\
\hline Infection & 47 & 36 \\
\hline CMV infection & 0 & 83 \\
\hline Complications specific to the organ/recipient & 7 & - \\
\hline Chronic rejection & 17 & 66 \\
\hline Malignancy & 10 & 73 \\
\hline Drug side effects & 17 & 66 \\
\hline Technical problems/graft thrombosis & 62 & 21 \\
\hline Nephrectomy & 8 & 75 \\
\hline
\end{tabular}

part of the process of transplantation remain similar to those for other surgical procedures.

This study shows a large variability in the amount of detail completed on consent forms for all patients undergoing renal transplantation, at a single unit in the UK. Such detail may not represent all that has been discussed with the patient but, at present, the consent form stands as the only contemporaneous record of what the patient has been informed about. Therefore, this work also highlights a previously reported lack of agreement among doctors regarding what risks should be discussed with patients undergoing renal transplantation. ${ }^{5}$ Interestingly, the authors also noted a variation in the risks mentioned by individual doctors with different patients.

In the UK, the standard of risk disclosure has long been governed by the Bolam principle. ${ }^{6}$ This states that the standard of information given to patients is judged by that which would be endorsed by the medical profession itself. However, in 1992 an ophthalmic surgeon in Australia was found negligent for not warning a patient of a 1 in 14000 risk of blindness. ${ }^{7}$ The court ruled that risks are material, and therefore patients should be informed of them, if a reasonable patient in the patient's position would find them significant. However, in this study it seems that the doctors obtaining consent seem more inclined to mention common surgical complications, such as bleeding and infection, and not the potentially more serious and significant complications, such as the risk of malignancy or need for nephrectomy.

Calls have been made for the development of procedure specific forms so that some consensus can be achieved as to which risks should be discussed $^{8} 9$ Such forms would eliminate the variations in consenting practice between different doctors and those over time by individual doctors. Having discovered these inadequacies, we are currently developing a renal transplant specific consent form, for use in our unit, and hope to repeat this audit once it is established in our practice.

One surgical consultant distributed an information leaflet to three patients. The use of such leaflets has been shown to

\begin{tabular}{lll}
$\begin{array}{l}\text { Table } 2 \\
\text { consent }\end{array}$ & Grade and specialty of doctors obtaining \\
\hline Specialty & Grade & Number of patients \\
\hline Surgery & Consultant & 62 \\
& SpR & 9 \\
\multirow{4}{*}{ Renal medicine } & SHO & 0 \\
& Consultant & 0 \\
& SpR & 4 \\
& SHO & 7 \\
\hline
\end{tabular}

be a useful adjunct in the process of obtaining consent that is favoured by patients, improves their recall of the facts discussed, and provides a record of the discussion. ${ }^{10}$ In addition, it allows the patient to access as much or as little information as they desire, in their own time. A potential alternative to this would be the use of web based information, which has been shown to be popular in the education of patients undergoing plastic surgery. ${ }^{11}$ However, little work has been carried out on the use of the internet in gaining informed consent in the UK. Over the years there has been concern over the accuracy of medical information provided on the internet, ${ }^{12}$ but, dedicated sites set up by each transplant unit, such as that of the transplant unit at Addenbrooke's Hospital, Cambridge, ${ }^{13}$ eliminates such worries. Provided that patients have internet access, this is a potentially useful method of providing unit specific information, which is yet to be fully exploited.

Obtaining consent for renal transplantation is known to be a complex process, whereby risks, benefits, complications, and alternatives are discussed, by a number of healthcare professionals, over a period of time. The consent form, on the other hand, is usually completed immediately before surgery and therefore does not represent all the discussions that may have taken place in the process of gaining valid, informed consent. There are a number of ways to ensure that all of the discussion that precedes the day of surgery is recorded. In the government's NHS plan, by April 2004, all patients should receive copies of clinic letters sent between health professionals. ${ }^{14}$ If letters are dictated to include what has been discussed with the patient then these could serve as a useful adjunct to the process of gaining consent. An alternative, but more expensive, tool, is to provide patients with an audio tape of their consultations. Much research has been performed into the use of such tapes from both the patients' and the health professionals' perspective. ${ }^{15}$ They have been shown to improve patient recall and improve their satisfaction with the information that they received. Doctors, however, have divided opinions with the use of tapes being seen as either providing sound medicolegal defence or as being medicolegally "risky". As well as recording what may have been discussed with the patient for medicolegal reasons, both clinic letters and audio tapes provide patients with a further source of information that they can refer to repeatedly.

In this series, all forms were completed on the day of or the day before surgery. At present there are no rules governing the ideal time to gain consent. There is evidence that both patients and clinical negligence solicitors feel consent should be obtained two weeks before elective procedures. ${ }^{16}$ This allows the patient to make decisions about treatment well in advance, without the concerns and anxieties associated with 
the immediate preoperative period. However, the circumstances of cadaveric renal transplantation are different to those of any other surgery as people with end stage renal failure are put onto a waiting list. As there is no way of predicting when a suitable organ will become available it is impossible to complete the consent form a few weeks in advance. To overcome this problem some units ask patients to complete their forms before they are put on the waiting list. This ensures that only patients who have made an informed decision about transplantation are put on the list. However, there is an ever growing discrepancy between the number of people awaiting a transplant and the number of organs donated. In the UK, patients spend a median time of 714 days on the waiting list. ${ }^{17}$ In individual centres this figure ranges from 305-1236 days. Given the length of time that some patients have to wait for a transplant, it is questionable whether a consent form completed several years previously is still valid at the time of transplantation.

We believe that when patients are first considered for transplantation they should be provided with an information leaflet. If after further discussion with health professionals they wish to proceed, they should be put on the waiting list. At the same time a checklist should be filed in the patients notes where risks and complications can be ticked off as they are discussed by different health professionals. By the time the patient arrives for surgery the surgeon can look down this checklist, decide what risks need to be discussed or reiterated, and then complete the procedure specific form.

That renal physicians were the doctors obtaining consent in 11 cases is probably a result of the practice in our unit, where transplant patients are cared for on renal medicine, rather than surgical, wards. However, it is generally recognised that the doctor gaining consent should be the person performing, or someone capable of performing, the procedure in question. ${ }^{18}$ It is, therefore, in the operating surgeons interests to ensure that they are the consenting health professional.

The absence of a consent form in $10 \%$ of notes is worrying. As the only record of what has been discussed with the patient we believe that the operating surgeon should complete the form in as detailed a fashion as possible, and ensure that the completed form is filed in the notes, next to the operation note.

\section{Authors' affiliations}

A G Edwards, A R Weale, J D Morgan, Department of Surgery, Southmead Hospital, Bristol, UK

Funding: none.

Conflicts of interest: none declared.

\section{REFERENCES}

1 Department of Health. Consent. http://www.dh.gov.uk.

2 The Bristol Royal Infirmary Inquiry. http://www.bristol-inquiry.org.uk.

3 The Royal Liverpool Children's Inquiry. http://www. parliament.thestationery-office.co.uk.

4 The Human Tissue Bill. http://www.parliament.the-stationery-office.co.uk.

5 McLaren A, Morris-Stiff G, Casey J. Issues of consent in renal transplantation. Ann R Coll Surg Engl 2001;83:343-6.

6 Bolam v Friern Hospital Management Committee [1957] 1 WLR 582.

7 Rogers $v$ Whitaker [1992] 67 AWR 47.

8 Sunil S, Austin R, Sinha S. Issues of consent in renal transplantation. Ann R Coll Surg Engl 2003;85:144-45.

9 Lloyd T, Millett A, Garcea G, et al. The new consent form: are we performing informed consent. Ann R Coll Surg Engl Suppl 2003;85:354-5.

10 Langdon IJ, Hardin R, Learmonth ID. Informed consent for total hip arthroplasty: does a written information sheet improve recall by patients? Ann R Coll Surg Engl 2002;84:404-8.

11 Webber WB, Summers AN, Rinehart GC. Computer-based multimedia in plastic surgery education. Plast Reconstr Surg 1994;93:1290-300.

12 Soot LC, Moneta GL, Edwards JM. Vascular surgery and the internet: a poor source of patient-oriented information. J Vasc Surg 1999;30:84-91.

13 Addenbrooke's Transplant Unit. http://cambridge-transplant.org.uk/ index.html.

14 Cowan J. Copying letters to patients: using clinical risk management to minimise problems. Clinical Governance: An International Journal 2003;8:360-3.

15 Tattersall MH, Butow PN. Consultation audio tapes: an underused cancer patient information aid and clinical research tool. Lancet Oncol 2002;3:431-7

16 Mayberry MK, Mayberry JF. Towards better informed consent in endoscopy: a study of information and consent processes in gastroscopy and flexible sigmoidoscopy. Eur J Gastroenterol Hepatol $2001 ; 13: 1467-76$

17 Rudge CJ, Fuggle SV, Burbidge KM. Geographic disparities in access to organ transplantation in the United Kingdom. Transplantation 2003;76:1395-8.

18 Dawes V. Seniors must sign in consent change. Hospital Doctor 1997;Feb 6:3. 